\title{
SISTEM INFORMASI REKAM MEDIS MENGGUNAKAN JAVA DI KLINIK KASIH IBU SEJAHTERA
}

\author{
Een Juhriah', Dewi Leyla Rahmah² \\ ${ }^{1,2}$ Universitas Indrapraasta PGRI \\ Jl.Raya Tengah No.80, Gedong, Pasar Rebo, Jakarta Timur \\ 1eenzuhriah29@gmail.com, ${ }^{2}$ leyladewiiskandar@gmail.com.com
}

\begin{abstract}
ABSTRAK
Kemajuan teknologi komputer yang begitu cepat sehingga masuk di berbagai lini kehidupan, termasuk dalam bidang kesehatan.Pada Klinik Kasih Ibu Sejahtera pengelolahan data masih menggunakan lembaran kertas sehingga membutuhkan waktu yang cukup lama dalam proses pencarian datanya. Sehingga dibutuhkan program dalam mengelolah ini semua. Metode yang digunakan dalam penelitian ini adalah menggunakan model Waterfall. Dengan adanya penerapan sistem komputer ini diharapkan dapat mempermudah pekerjaan pengolahan data rekam medis. Selain itu dapat mengatasi masalah yang ada pada sistem yang lama sehingga mampu memenuhi semua kebutuhan sistem. Aplikasi rekam medis ini di buat dengan program java dan databases MySql serta menggunakan editor netbeans 8.2. Adapun metode yang digunakan dalam pengumpulan data adalah observasi, wawancara dan studi pustaka. Penelitian ini menghasilkan sebuah aplikasi berupa program rekam medis yang lebih user friendly dan menyimpan data pasien, data rekam medis, data transaksi, data layanan sehingga memudahkan dalam mengintegrasikan data di klinik ibu sejahtera.
\end{abstract}

Kata Kunci: rekam medis, java,Sistem Informasi

\begin{abstract}
Advances in computer technology are so fast that they are included in various lines of life, including in the health sector. At the Kasih Ibu Sejahtera Clinic, data processing is still using sheets of paper, so it takes a long time to find the data. So a program is needed to manage all of this. The method used in this research is using the Waterfall model. With the application of this computer system is expected to facilitate the work of processing medical record data. In addition, it can overcome the problems that exist in the old system so that it is able to meet all system needs. This medical record application is made with java programs and MySQL databases and uses the netbeans 8.2 editor. The methods used in data collection are observation, interviews and literature study. This research produces an application in the form of a medical record program that is more user friendly and stores patient data, medical record data, transaction data, data services, making it easier to integrate data at the Prosperous Mothers clinic.
\end{abstract}

Key Word: medical record, java, information system

\section{PENDAHULUAN}

Teknologi informasi merupakan salah satu teknologi yang sedang berkembang dengan pesat pada saat ini. Di Indonesia sendiri informasi sudah menjadi kebutuhan pokok dalam berbagai sektor, hal ini ditandai dengan munculnya berbagai aspek sistem informasi di pemerintahan, lembagalembaga swasta, individu maupun kelompok, semuanya sudah menggunakan teknologi informasi sebagai alat pendukung pekerjaannya.

menurut (Kadir, 2014), Sistem informasi adalah sebuah rangkaian prosedur formal dimana data dikelompokkan, diproses menjadi informasi, dan didistribusikan kepada pemakai. Pengertian menurut (Krismaji, 2015) Sistem informasi adalah cara-cara yang diorganisasi untuk mengumpulkan, memasukkan, dan mengolah serta menyimpan data, dan cara-cara yang diorganisasi untuk menyimpan, mengelola, mengendalikan, dan melaporkan informasi sedemikian rupa sehingga sebuah organisasi dapat mencapai tujuan yang telah ditetapkan.(Romney \& Steinbart, 2015)

Pasien adalah orang yang memiliki kelemahan fisik atau mentalnya menyerahkan pengawasan dan perawatannya, menerima dan mengikuti pengobatan yang ditetapkan oleh tenaga kesehatan yang dikemukakan oleh Prabowo (dalam Wilhamda, 2011) (Mukhayaroh, 2018)

Rekam medis adalah berkas berisi catatan tentang pasien, yang dibuat berdasarkan kronologis waktu. Terdapat dua jenis rekam medis dan secara umum telah diatur dalam 
Permenkes

Nomor:

269/MENKES/PER/III/2008 tentang Rekam

Medis.(Samandari, Chandrawila S, \& Rahim, 2017)

Pendataan Rekam Medis di Klinik Kasih Ibu Sejahtera masih menggunakan cara manual. Hal itu dirasakan kurang efektif dan tidak efisien, karena harus membuat beberapa perubahan jika ada informasi baru yang masuk, banyak terjadi penyimpanan data ganda dan pada saat pembuatan laporan memerlukan waktu yang sangat lama karena harus memeriksa semua data pasien terlebih dahulu. Dampak dari masalah tersebut yaitu kurangnya informasi dan pembuatan laporan yang terkomputerisasi mengenai rekam medis pasien, karena belum tersedianya aplikasi khusus rekam medis pasien dan data yang didapat ditulis secara manual yang memungkinkan data pasien akan menjadi bercampur satu dengan yang lain.

Berdasarkan latar belakang masalah diatas penulis dapat mengambil kesimpulan tentang identifikasi masalah sebagai berikut: 1)Aplikasi ini dibuat untuk membantu petugas medis dalam mengolah data rekam medis secara komputerisasi pada klinik Kasih Ibu Sejahtera 2)Sistem informasi yang digunakan oleh Klinik Kasih Ibu Sejahtera masih bersifat manual dalam pengelolaan data medis pasien.

\section{METODE PENELITIAN}

Metode yang digunakan dalam penelitian ini menggunakan Model waterfall. Model waterfall adalah model yang paling banyak digunakan untuk tahap pengembangan. Model waterfall ini juga dikenal dengan nama model tradisional atau model klasik.Model air terjun (waterfall) sering juga disebut model sekuensial linier (squential linear) atau alur hidup klasik (Classic cycle)". Model air terjun ini menyediakan pendekatan alur hidup perangkat lunak secara sekuensial terurut dimulai dari analisis, desain, pengkodean, pengujian dan tahap pendukung (support).

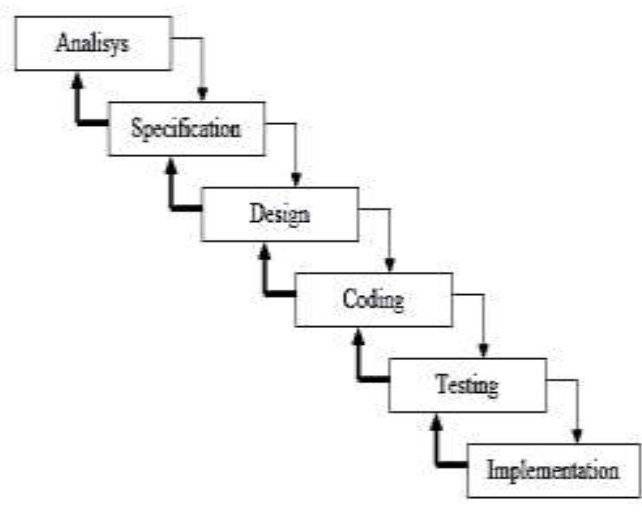

Gambar 1. Metode Waterfall

Adapun tahapan dalam pengumpulan memperoleh data sebagai berikut :

\section{Observasi}

Peneliti melakukan kunjungan ke Klinik Kasih Ibu Sejahtera untuk mengetahui masalah yang dihadapi pada sistem yang sedang berjalan. Dan melakukan pengamatan terhadap proses pelayanan pada Klinik Kasih Ibu Sejahtera, sehingga peneliti dapat menentukan suatu masalah sehingga dapat dengan segera mengevaluasi kebutuhan sistem dan merancang sistem pada Klinik Kasih Ibu Sejahtera.

2. Wawancara

Peneliti melakukan wawancara kepada pihak-pihak yang terkait, baik pihak tenaga medis maupun kepala klinik.

3. Studi Pustaka

Melakukan penelitian berarti mencoba mencari solusi atas suatu permasalahan yang dilakukan dengan cara-cara ilmiah, salah satunya dengan melakukan studi pustaka. Studi pustaka merupakan teknik pengumpulan data dan informasi dengan menelaah sumber-sumber tertulis seperti jurnal ilmiah, buku refernsi, literatur, ensiklopedia, karangan ilmiah, serta sumber-sumber lain yang terpercaya baik dalam bentuk tulisan atau dalam format digital yang relevan dan berhubungan dengan objek yang sedang diteliti. 


\section{HASIL DAN PEMBAHASAN}

Sistem yang baik adalah sistem yang dapat berfungsi atau berjalan sesuai dengan prosedur yang berlaku sehingga menghasilkan output yang diinginkan sehingga mencapai tujuan yang direncanakan.

Beberapa tahapan prosedur sistem yang sedang berjalan:

1. Bagian pendaftaran menanyakan Kartu Berobat pasien (untuk pasien lama) atau mencatat data atau identitas pasien dengan lengkap (untuk pasien baru).

2. Menanyakan kepada pasien tentang poli yang akan dituju.

3. Bagian pendaftaran menyerahkan pendaftaran pasien kebagian rekam medik untuk dicarikan berkas status pasien rawat jalan sesuai dengan nomor rekam medik dan selanjutnya status pasien rawat jalan diantarkan oleh petugas rekam medik ke poli yang dituju.

4. Arahkan pasien kepoli yang dituju memberikan kartu berobat pasien.

5. Setelah pasien sudah melakukan pemeriksaan oleh rekan dokter, kemudian pasien menuju kasir untuk melakukan pembayaran.

6. Bagian Rekam Medik mencatat di buku kunjungan pasien, dimana pada proses rekam medik tersebut menghasilkan data rekam medik yang masuk ke dalam proses pembuatan laporan pasien baik laporan harian maupun laporan bulanan.

\section{Diagram Alir Data}

Data Flow Diagram atau dalam bahasa Indonesia menjadi Diagram Alir Data (DAD) adalah refresentasi grafik yang menggambarkan aliran Informasi dan transformasi informasi yang di aplikasikan sebagai data yang mengatur dari masukan (input) dan Keluaran(output)(Wieringa, 2003)

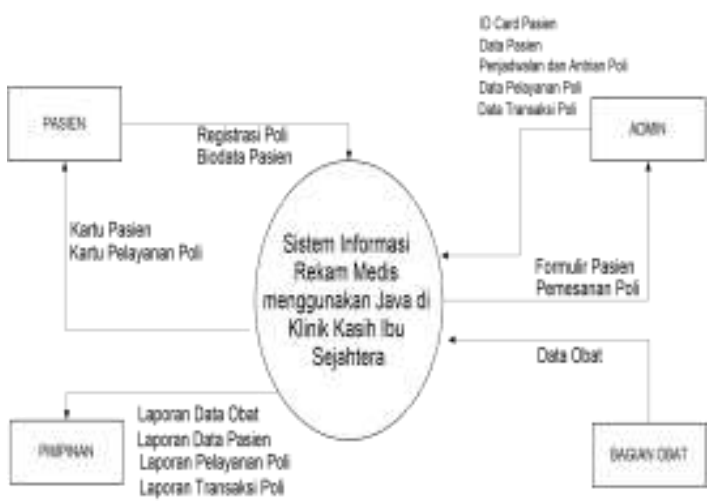

Gambar 2. Diagram Konteks

\section{Diagram Nol}

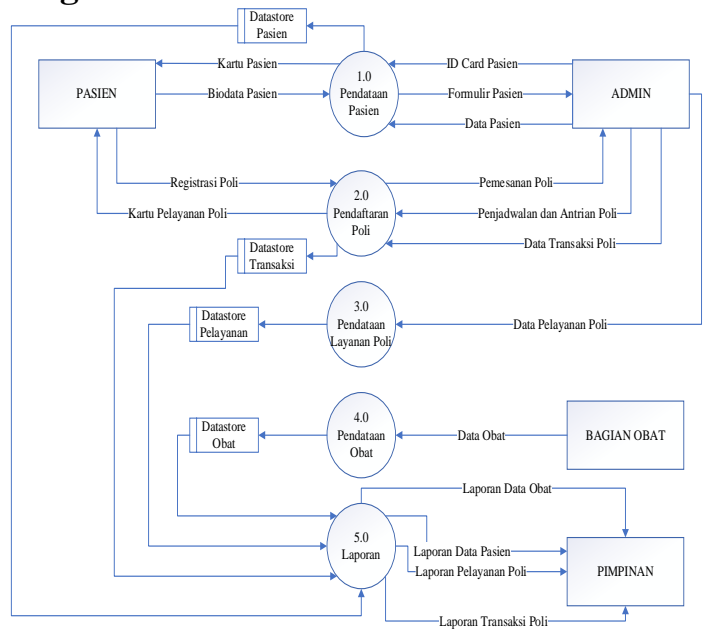

Gambar 3. Diagram Rinci

\section{Entity Relationship Diagram}

ERD adalah suatu model untuk menjelaskan hubungan antar data dalam basis data berdasarkan objek-objek dasar data yang mempunyai hubungan (Sukamto dan \& Shalahuddin, 2015)

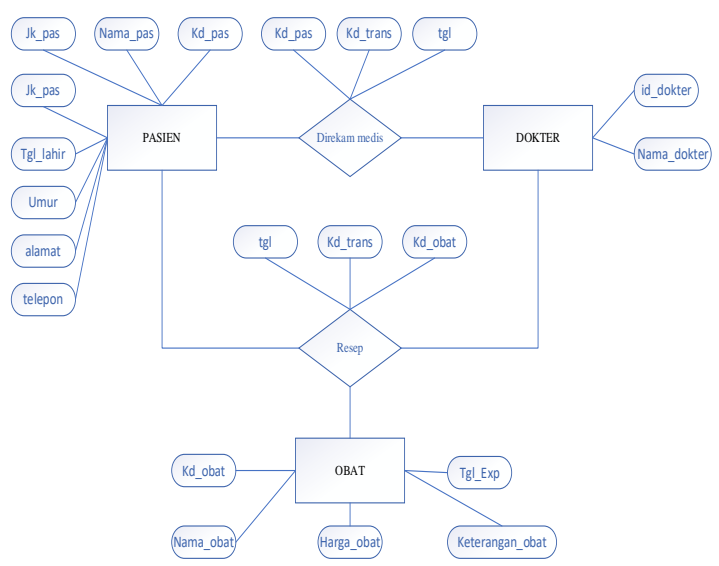

Gambar 4. ERD REKAM MEDIS

\section{Tampilan Login}

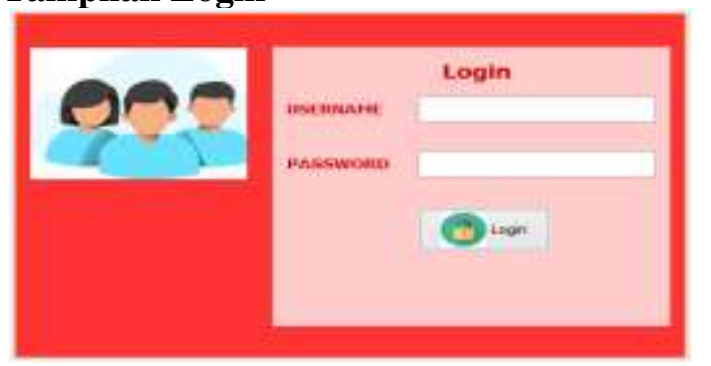

Gambar 5. Tampilan Login

Tampilan login muncul saat mulai pengoperasian aplikasi rekam medis psien klinik Kasih Ibu Sejahtera berbasis java. Admin memasukan username dan password agar bisa mengoperasikan sistem. 


\section{Tampilan Menu Utama}

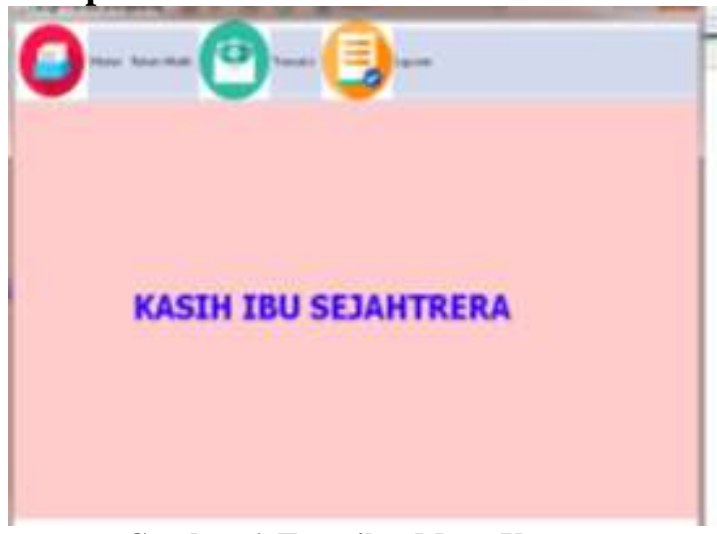

Gambar 6. Tampilan Menu Utama

Pada tampilan menu utama terdapat beberapa ikon menu yang akan menampilkan formform sebagai berikut:

1. Master Rekam Medik, form input ini untuk membuat kartu rekam medik setelah dibuatkan lalu mencetaknya untuk diberikan pada dokter. Semua data rekam medik yang telah terisi oleh dokter yang nantinya akan dijadikan sebagai arsip.

2. Transaksi, akan menampilkan data transaksi dan faktur faktur layanan pada klinik.

3. Laporan, akan menampilkan menu laporan yang berisi laporan master rekam medik dan transaksi.

Tampilan Layar Data Pasien

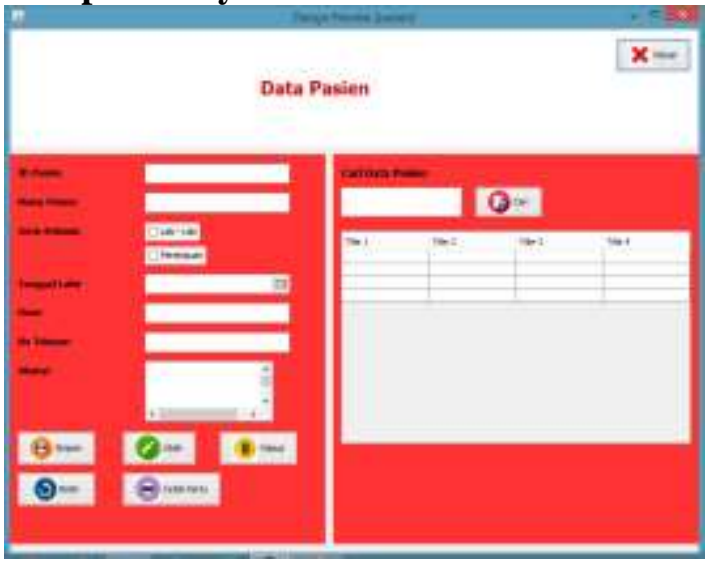

Gambar 7. Tampilan Data Pasien

Pada tampilan form data pasien, data calon pasien akan diinputkan pada form ini yang nantiya akan tersimpan untuk keperluan medis.
Tampilan Layar Data Oba

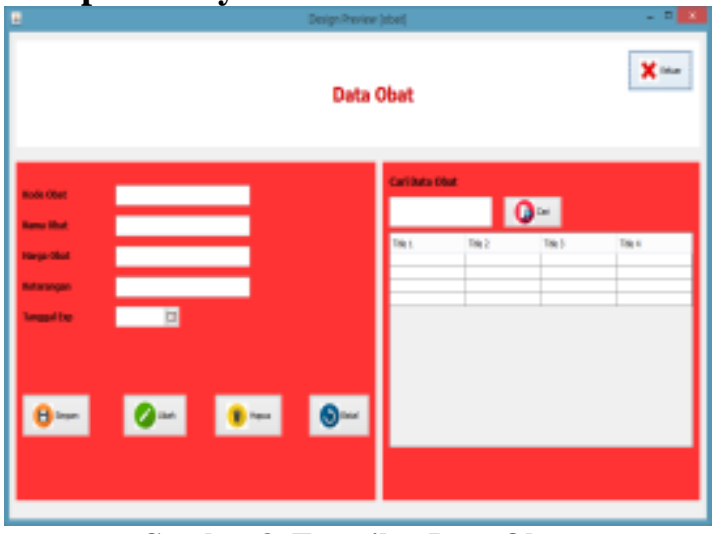

Gambar 8. Tampilan Data Obat

Pada tampilan form data obat akan diinputkan data obat, dan dapat menampilkan data obat yang dibutuhkan.

\section{Tampilan Layar Data Layanan}

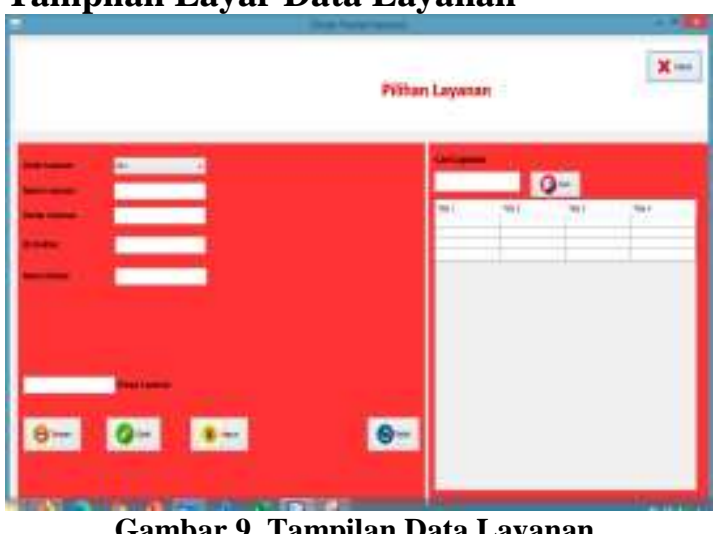

Pada tampilan data layanan akan menampilkan layanan yang ada pada klinik Ibu sejahtera. Layanan yang ada yaitu layanan poli dan umum.

\section{Pengujian Sistem}

Black Box Testing Pengujian perangkat lunak dari segi spesifikasi fungsional tanpa mengujidesain dan kode program untukmengetahui apakah fungsi, masukan dankeluaran dari perangkat lunak sesuai dengan spesifikasi yang dibutuhkan. Metode BlackboxTesting merupakan salah satu metode yang mudah digunakan karena hanya memerlukan batas bawah dan batas atas dari data yang di harapkan,Estimasi banyaknya data uji dapat dihitung melalui banyaknya field data entri yang akan diuji, aturan entri yang harus dipenuhi serta kasus batas atas dan batas bawah yang memenuhi. Dan dengan metode ini dapat diketahui jika fungsionalitas masih dapatmenerima masukan data yang 
tidak diharapkan maka menyebabkan data yangdisimpan kurang valid.

Tabel 1 Hasil Pengujian yang dilakukan oleh

\begin{tabular}{|c|c|c|c|}
\hline $\begin{array}{c}\text { Data } \\
\text { Masukan }\end{array}$ & $\begin{array}{c}\text { Kejadian } \\
\text { yang } \\
\text { diharpakan }\end{array}$ & $\underset{n}{\text { pengamata }}$ & $\underset{\mathrm{n}}{\text { Kesimpula }}$ \\
\hline $\begin{array}{c}\text { Login } \\
\text { dengan } \\
\text { id dan } \\
\text { password } \\
\text { yang } \\
\text { benar }\end{array}$ & $\begin{array}{c}\text { Masuk ke } \\
\text { dalam } \\
\text { menu } \\
\text { utama }\end{array}$ & $\begin{array}{c}\text { Berhasil } \\
\text { masuk } \\
\text { kemenu } \\
\text { utama }\end{array}$ & valid \\
\hline $\begin{array}{c}\text { Login } \\
\text { dengan } \\
\text { id dan } \\
\text { password } \\
\text { yang } \\
\text { salah }\end{array}$ & $\begin{array}{c}\text { Ada } \\
\text { peringatan } \\
\text { login salah } \\
\text { dan } \\
\text { kembali ke } \\
\text { form log in }\end{array}$ & $\begin{array}{c}\text { Gagal } \\
\text { masuk ke } \\
\text { manu } \\
\text { utama }\end{array}$ & gagal \\
\hline $\begin{array}{c}\text { Log ini } \\
\text { dengan } \\
\text { password } \\
\text { tidak } \\
\text { diisi }\end{array}$ & $\begin{array}{c}\text { Ada } \\
\text { peringatan } \\
\text { login salah } \\
\text { dan } \\
\text { kembali ke } \\
\text { form log in }\end{array}$ & $\begin{array}{c}\text { Gagal } \\
\text { masuk ke } \\
\text { manu } \\
\text { utama }\end{array}$ & gagal \\
\hline $\begin{array}{l}\text { Input } \\
\text { data } \\
\text { registrasi } \\
\text { pasien }\end{array}$ & $\begin{array}{c}\text { Masuk } \\
\text { kedalam } \\
\text { database } \\
\text { dan dapat } \\
\text { menginput } \\
\text { data pasien } \\
\text { dan masuk } \\
\text { kedalam } \\
\text { database }\end{array}$ & $\begin{array}{l}\text { Berhasil } \\
\text { input data } \\
\text { registrasi } \\
\text { pasien ke } \\
\text { database } \\
\text { sistem }\end{array}$ & valid \\
\hline $\begin{array}{c}\text { Input } \\
\text { data obat }\end{array}$ & $\begin{array}{c}\text { Masuk } \\
\text { kedalam } \\
\text { database } \\
\text { dan dapat } \\
\text { menginput } \\
\text { data pasien } \\
\text { dan masuk } \\
\text { kedalam } \\
\text { input data } \\
\text { obat }\end{array}$ & $\begin{array}{l}\text { Berhasil } \\
\text { input data } \\
\text { obat ke } \\
\text { database } \\
\text { sistem }\end{array}$ & valid \\
\hline $\begin{array}{c}\text { Input } \\
\text { data } \\
\text { pelayana } \\
\text { n }\end{array}$ & $\begin{array}{c}\text { Masuk } \\
\text { kedalam } \\
\text { data } \\
\text { pelayanan } \\
\text { dan masuk } \\
\text { kedalam } \\
\text { data base }\end{array}$ & $\begin{array}{l}\text { Berhasil } \\
\text { input } \\
\text { pelayana } \\
\text { ke dalam } \\
\text { database }\end{array}$ & valid \\
\hline $\begin{array}{c}\text { Edit Data } \\
\text { Pelayana } \\
\text { n }\end{array}$ & $\begin{array}{c}\text { Data } \\
\text { layanan } \\
\text { diperbahur } \\
\text { ui }\end{array}$ & $\begin{array}{c}\text { Berhasil } \\
\text { merubah } \\
\text { data } \\
\text { layanan }\end{array}$ & valid \\
\hline $\begin{array}{c}\text { Delete } \\
\text { data } \\
\text { layanan }\end{array}$ & $\begin{array}{c}\text { Data } \\
\text { layanan } \\
\text { dari } \\
\text { database }\end{array}$ & $\begin{array}{c}\text { Berhasil } \\
\text { menghapu } \\
\text { s data } \\
\text { layanan } \\
\text { dari } \\
\text { database } \\
\end{array}$ & valid \\
\hline
\end{tabular}

\section{Tampilan Layar Data Transaksi}

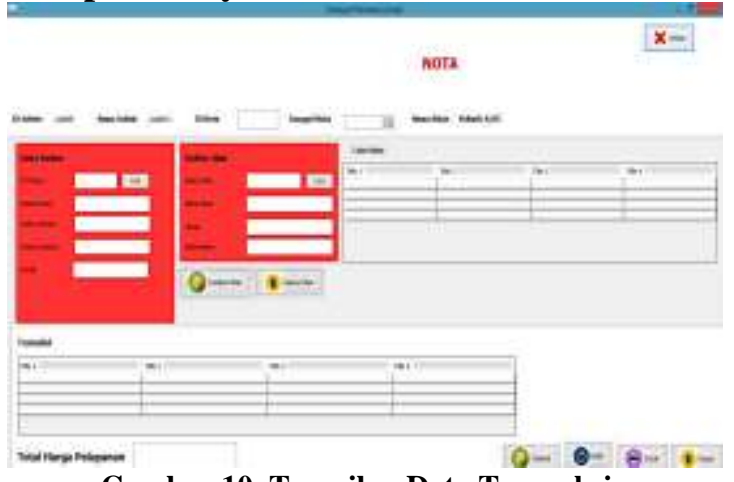

Gambar 10. Tampilan Data Transaksi

Pada tampilan ini dapat menampilkan data transaksi pasien yang telah tersimpan dalam database, output berupa nota.

\section{Laporan data Pasien}

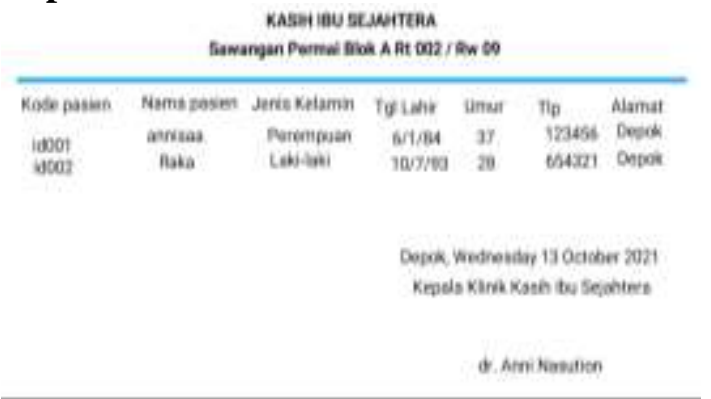

Gambar 11. Laporan Data Pasien

\section{Laporan Rekam Medis KLINIK KASIH IBU SEJAHTRERA Saxangan Peemai Blick A Rt 002/ Rw 09}

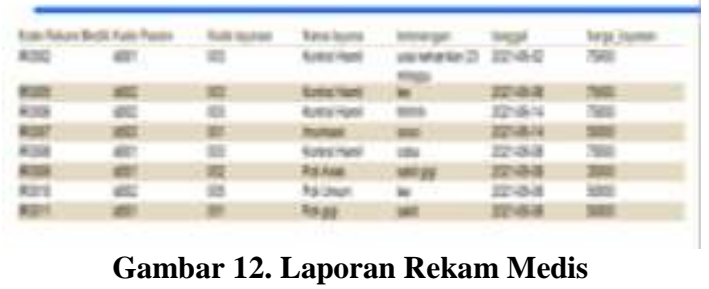

Berikut adalah tampilan laporan rekam medis, dimana dapat menampilkan kode rekam medik, kode pasien, kode layanan, nama layanan dan tanggal layanan.

\section{SIMPULAN DAN SARAN}

Dari penelitian dan pembahasan, maka dapat disimpulkan bahwa: 1) Pengunaan sistem informasi rekam medis Klinik Kasih Ibu Sejahtera berjalan dengan baik sehingga dapat memudahkan operator dalam menjalankannya. 2) Penyimpanan data pasien, data rekam medis dan lainnya menjadi lebih 
rapih dan memudahkan dalam mengintegrasikan data Klinik Kasih Ibu Sejahtera.

Adapun saran yang dapat dijadikan untuk penelitian selanjutnya yaitu: 1) Sistem informasi rekam medic Klinik Kasih Ibu Sejahtera perlu dikembangkan agar sistem yang nantinya dapat menggunakan peralatan seperti perangkat mobile sebagai inputannya. 2) Perlu adanya pembaharuan data penyimpanan setiap tahunnya agar data bisa terselamatkan apabila terjadi kerusakan pada komputer. 3) Perlu adanya pengembangan menjadi aplikasi berbasis online supaya pasien lebih mudah dalam berinteraksi.

\section{DAFTAR PUSTAKA}

Mukhayaroh, A. (2018). Metode Rapid Aplication Development Pada Sistem Informasi Rekam Medis Pasien Rawat Jalan. Informatics For Educators And Professionals, 3(1).

Mustaqbal, M.S.M., Firdaus, R.F.F.,\& Rahmadi, H.R. (2015). Pengujian Aplikasi Menggunakan Black Box TestingBoundary Value Analysis (Studi Kasus Aplikasi Prediksi Kelulusan SNMPTN). Jurnal Ilmiah
Teknologi Terapan (JITTER),; 1(3):3136.

Prayitno, A., \& Safitri, Y. (2015). Pemanfaatan Sistem Informasi

Perpustakaan Digital Berbasis Website Untuk Para Penulis , Indonesian

Journal on Software Engineering, (1) 1, 24610690.

Romney, M. B., \& Steinbart, P. J. (2015). Accounting information systems. In Information Technology and Innovation Trends in Organizations ItAIS: The Italian Association for Information Systems.

Samandari, N. A., Chandrawila S, W., \& Rahim, A. H. (2017). Kekuatan Pembuktian Rekam Medis Konvensional dan Elektronik. Soepra, 2(2). https://doi.org/10.24167/shk.v2i2.818

Sukamto dan, \& Shalahuddin(2015:29). (2015). Shalahuddin, M. Rosa A.S 2015. Rekayasa Perangkat Lunak Terstruktur dan Berorientasi Objek. Edisi REVISI. In Informatika Bandung.

Wieringa, R. J. (2003). Data Flow Diagrams. In Design Methods for Reactive Systems. https://doi.org/10.1016/b978155860755-2/50022-8 